\title{
Active Management of Electric Vehicles Acting as Distributed Storage
}

\author{
F. J. Soares*, INESC Technology and Science (INESC TEC), Porto, Portugal \\ P. M. Rocha Almeida, Smarter Grid Solutions Ltd, Glasgow, United Kingdom \\ Matthias Galus, Swiss Federal Office of Energy, Zürich, Switzerland \\ P. N. Pereira Barbeiro, INESC Technology and Science (INESC TEC), Porto, Portugal \\ J. A. Peças Lopes, FEUP \& INESC Technology and Science (INESC TEC), Porto, Portugal
}

\begin{abstract}
In the European Union (EU), the greenhouse emissions from the transportation sector increased around 36\% since 1990, which degraded the environmental quality. This sector, due to its oil dependency, is responsible for around a quarter of EU greenhouse emissions, and the road transportation represents about $20 \%$ of the total $\mathrm{CO}_{2}$ emissions in EU. Moreover, concerns such as the dependency on oil supply and the foreseen prices increase during this century have motivated a wide range of policy and technological measures for the transportation sector. A large part of these measures were to incentivize the Electric Vehicle (EV) adoption, which is one element with great potential to decarbonize the transportation sector and decrease its oil dependency.

This chapter describes relevant methodologies to actively manage EV charging/discharging (as distributed storage devices) to achieve different goals, such as avoid grid congestion, the EV participation in primary frequency control and the coordination of EV charging with renewable generation. To contextualize the methodologies described, a brief state of the art in active management functionalities for EV is provided. Some of the results obtained with the described approaches are also presented to demonstrate their overall performance.
\end{abstract}

Keywords: Electric vehicles; Active charging/discharging management; Primary frequency control; Congestion management; Coordination with renewables availability.

\section{Introduction}

\subsection{Overview}

The high expectations concerning the potential of Electric Vehicles (EV) to reduce greenhouse gas emissions are essentially based on the reduction of fossil fuels consumption in the transportation sector that they will induce. However, to assure an effective reduction in fossil fuels consumption, the replacement of conventional vehicles by EV must be closely accompanied by a progressive increase of electricity generation exploiting Renewable Energy Sources (RES). Nevertheless, there is maximum threshold of RES, namely in the case of intermittent sources, after which there is a high risk of having renewable energy being wasted. In these cases, the EV storage capacity can potentially be used to increase the energy consumption when a renewable energy surplus exists, contributing to avoid wasting "clean" energy and thus enabling higher RES integration, (Lopes et al., 2009a). EV storage capability can also be used to perform primary frequency control in isolated systems, enabling the integration of a higher share of intermittent RES

${ }^{*}$ F. J. Soares, INESC TEC, Campus da FEUP, Rua Dr. Roberto Frias, 4200 - 465 Porto Portugal. Telf: +351 22 209 4212. Fax: +35122 209 4050. E-mail: fsoares@inescporto.pt 